Supporting Information for:

\title{
Mitochondria Targetable Time-Gated Luminescence Probe for Singlet Oxygen Based on a $\beta$-Diketonate-Europium Complex
}

\author{
Jingyan Sun, Bo Song, Zhiqiang Ye, Jingli Yuan*
}

State Key Laboratory of Fine Chemicals, School of Chemistry, Dalian University of Technology, Dalian 116024, P.R. China.

*To whom correspondence should be addressed.

E-mail: jlyuan@dlut.edu.cn 


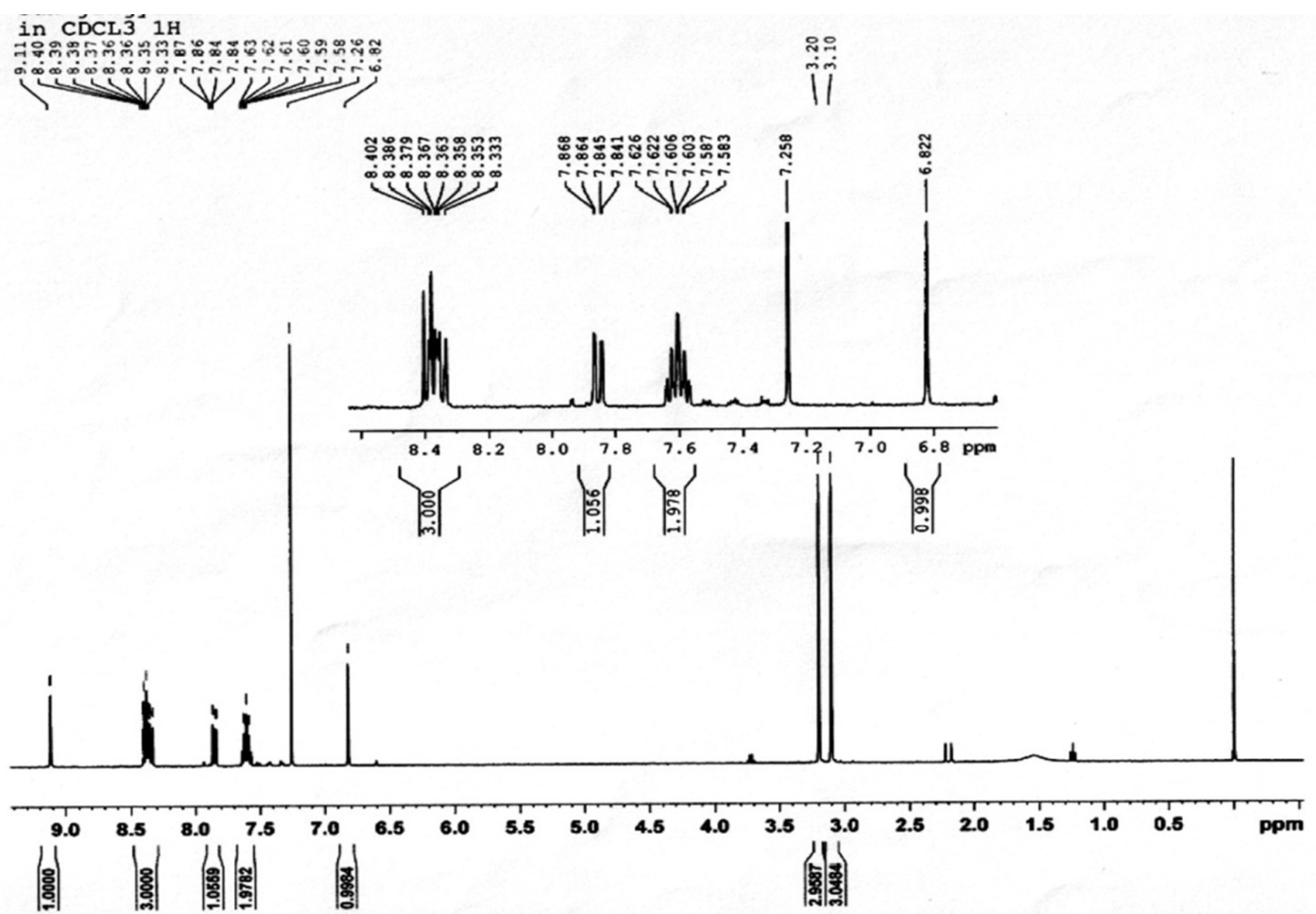

Figure S1. ${ }^{1} \mathrm{H}$ NMR spectrum of Hpfdap in $\mathrm{CDCl}_{3}$. 


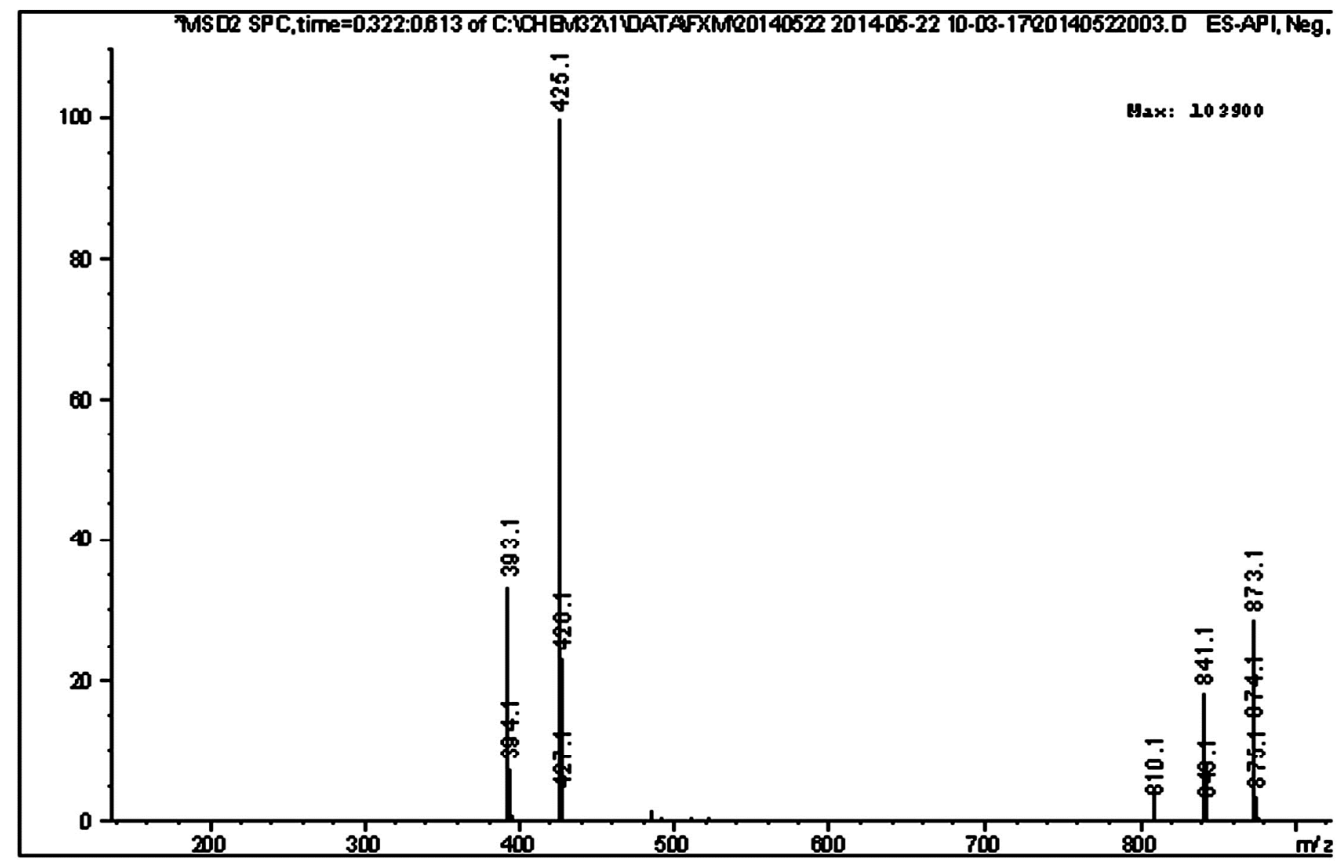

Figure S2. ESI-mass spectrum of Hpfdap. 


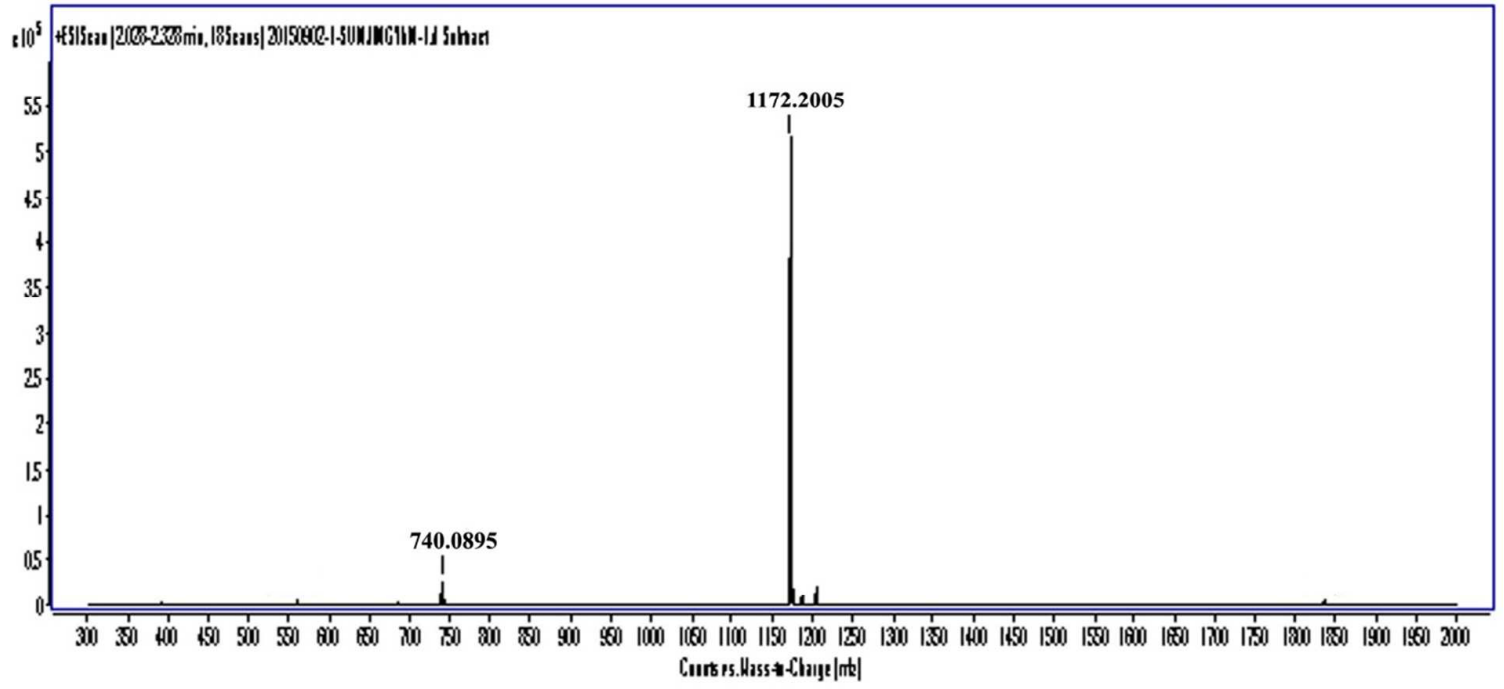

Figure S3. ESI-HR mass spectrum of [Eu(pfdap $)_{3}($ tpy) $]$. 


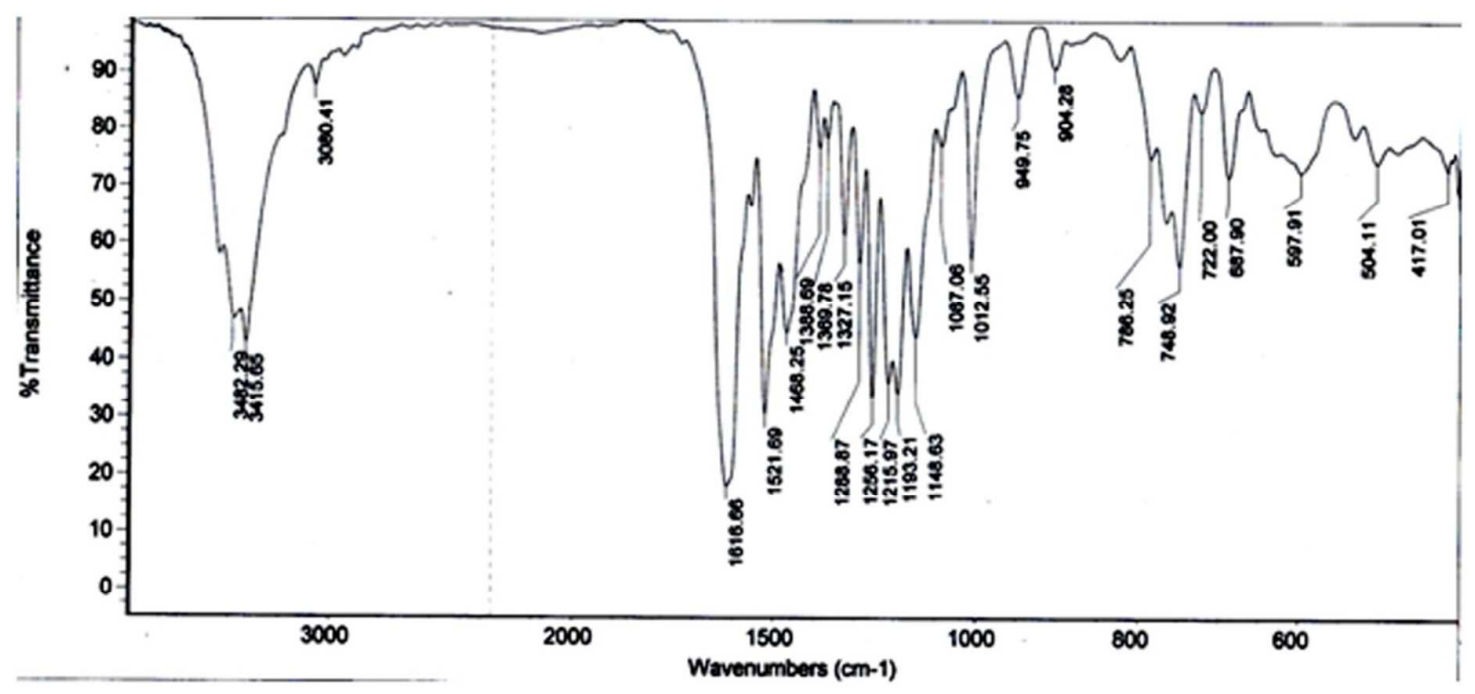

Figure S4. FT-IR spectrum of [Eu(pfdap) $)_{3}($ tpy) $]$. 


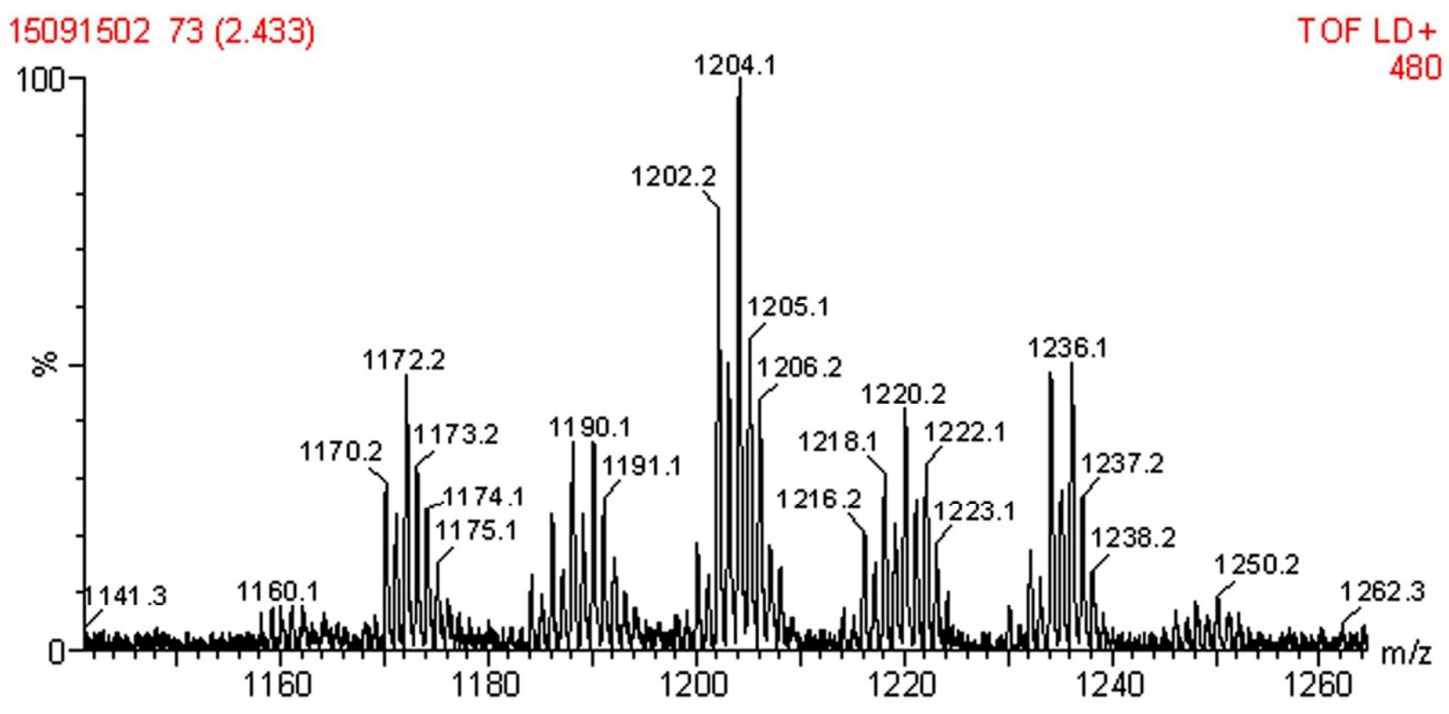

Figure S5. MALDI-TOF mass spectrum of the product of $\left[\mathrm{Eu}(\mathrm{pfdap})_{3}(\mathrm{tpy})\right]$ reacted with ${ }^{1} \mathrm{O}_{2}$ produced by the irradiation of a photosensitizer, TMPyP. 


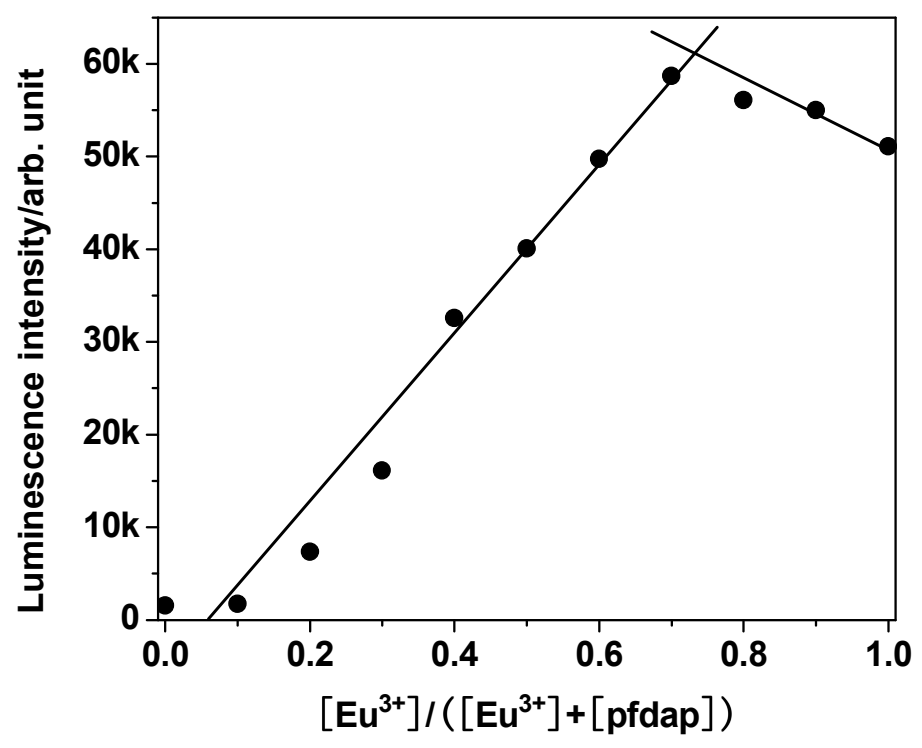

Figure S6. Job's plot of the reaction between $\mathrm{Eu}^{3+}$ and pfdap in $0.05 \mathrm{M}$ borate buffer of $\mathrm{pH} 7.2$ (the total concentration of $\mathrm{Eu}^{3+}$ and pfdap was kept at $\left.80 \mu \mathrm{M}\right)$. 


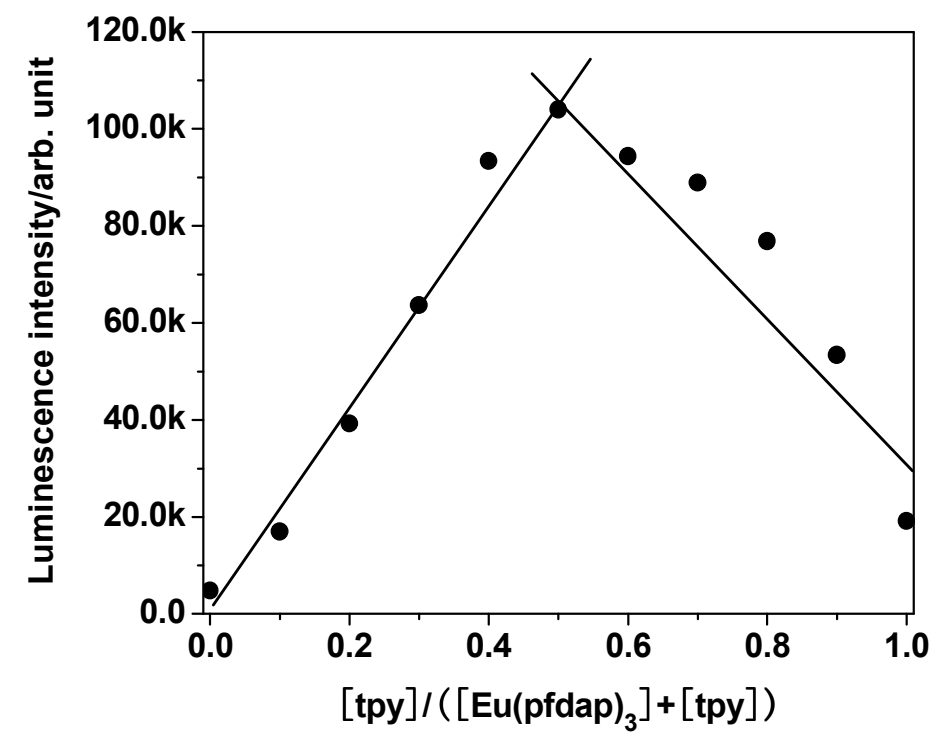

Figure S7. Job's plot of the reaction between $\left[\mathrm{Eu}(\mathrm{pfdap})_{3}\right]$ and tpy in $0.05 \mathrm{M}$ borate buffer of $\mathrm{pH}$ 7.2 (the total concentration of $\left[\mathrm{Eu}(\mathrm{pfdap})_{3}\right]$ and tpy was kept at $\left.40 \mu \mathrm{M}\right)$. 


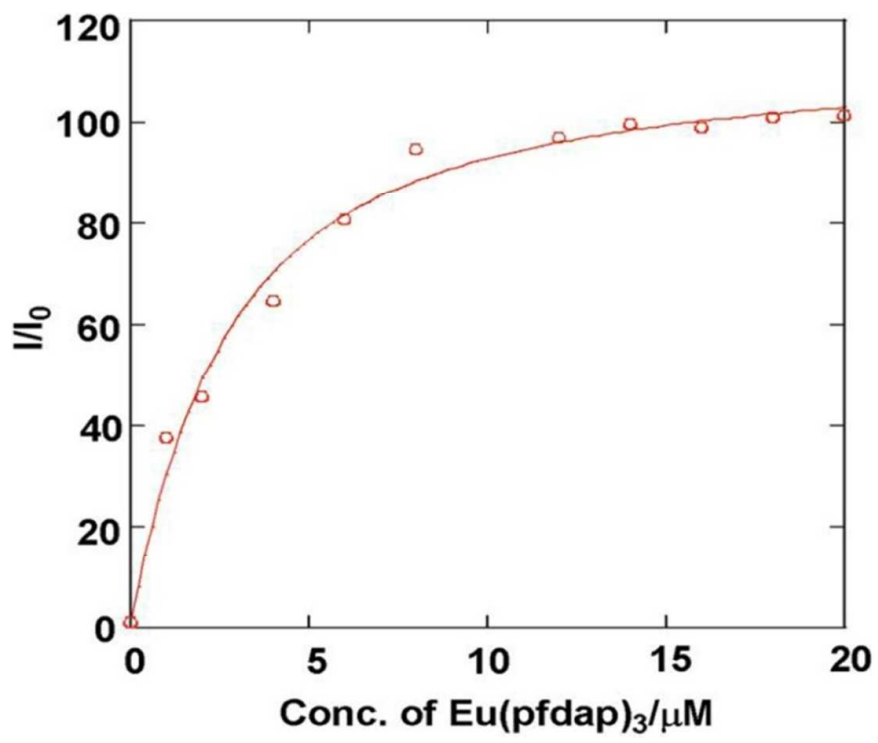

Figure S8. Luminescence titration results of tpy $(10 \mu \mathrm{M})$ with different amounts of Eu(pfdap $)_{3}(1.0$ $\mathrm{mM}$ ) in $0.05 \mathrm{M}$ borate buffer at $\mathrm{pH}$ 7.2. The resulting luminescence titration curve was analyzed by a non-linear regression based on a 1:1 binding isotherm model. ${ }^{\text {S1 }}$ Upon additions of various concentrations of $\mathrm{Eu}(\mathrm{pfdap})_{3}$, the luminescence intensity of Eu(pfdap) $)_{3}(\mathrm{tpy})$ can be fitted by the equation: $\mathrm{I} / \mathrm{I}_{0}=\left\{1+\left(\mathrm{I}_{\max }-\mathrm{I}_{0}\right) K_{11}\left[\mathrm{Eu}(\text { pfdap })_{3}\right]\right\} /\left\{1+K_{11}\left[\mathrm{Eu}(\text { pfdap })_{3}\right]\right\}$. In the equation, $K_{11}$ is association constant of typ and $\mathrm{Eu}(\text { pfdap })_{3}$, I is the luminescence intensity, $\mathrm{I}_{\max }$ is the maximum luminescence intensity, $\mathrm{I}_{0}$ is the luminescence intensity without addition of $\mathrm{Eu}(\mathrm{pfdap})_{3}$, and $\left[\mathrm{Eu}(\mathrm{pfdap})_{3}\right]$ is the concentration of free $\mathrm{Eu}(\mathrm{pfdap})_{3}$, which can be related to the known initial concentrations of $\mathrm{Eu}(\text { pfdap })_{3}\left(\left[\mathrm{Eu}(\text { pfdap })_{3}\right]_{0}\right)$ and the complex $\operatorname{Eu}(\text { pfdap })_{3}($ tpy $)\left(\mathrm{C}_{0}\right)$ in the next equation: $\left[\mathrm{Eu}(\text { pfdap })_{3}\right]_{0}=\left[\mathrm{Eu}(\text { pfdap })_{3}\right]+\left\{\mathrm{C}_{0} K_{11}\left[\operatorname{Eu}(\text { pfdap })_{3}\right]\right\} /\left\{1+K_{11}\left[\mathrm{Eu}(\text { pfdap })_{3}\right]\right\}$

Ref. S1. K. A. Connors, Binding Constants, John Wiley \& Sons, Inc., New York, 1987, p. 339. 


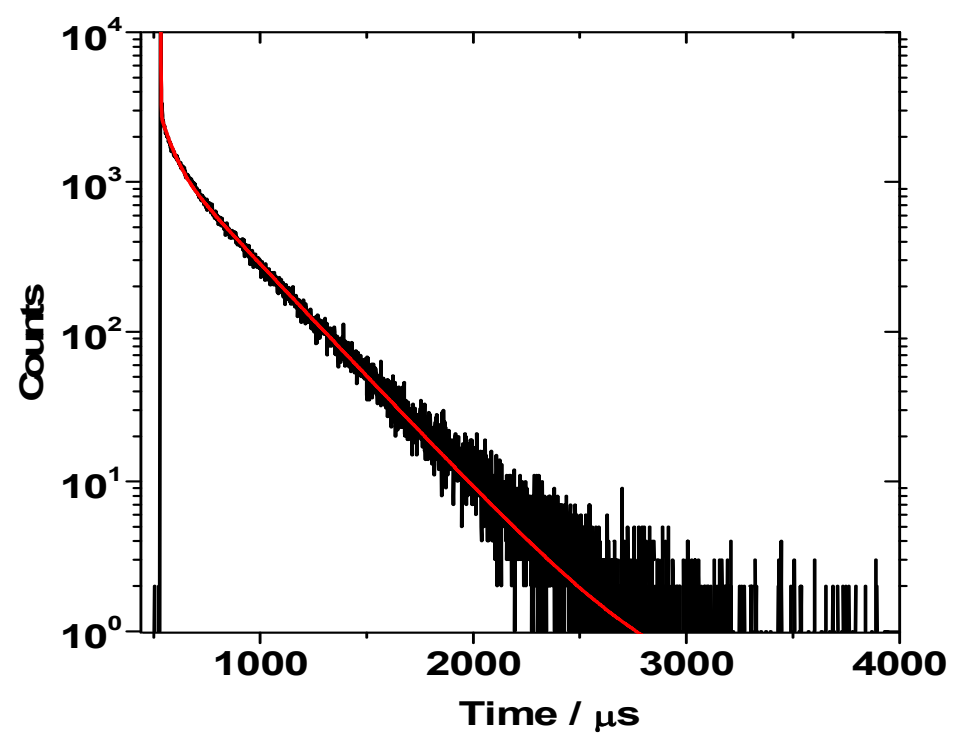

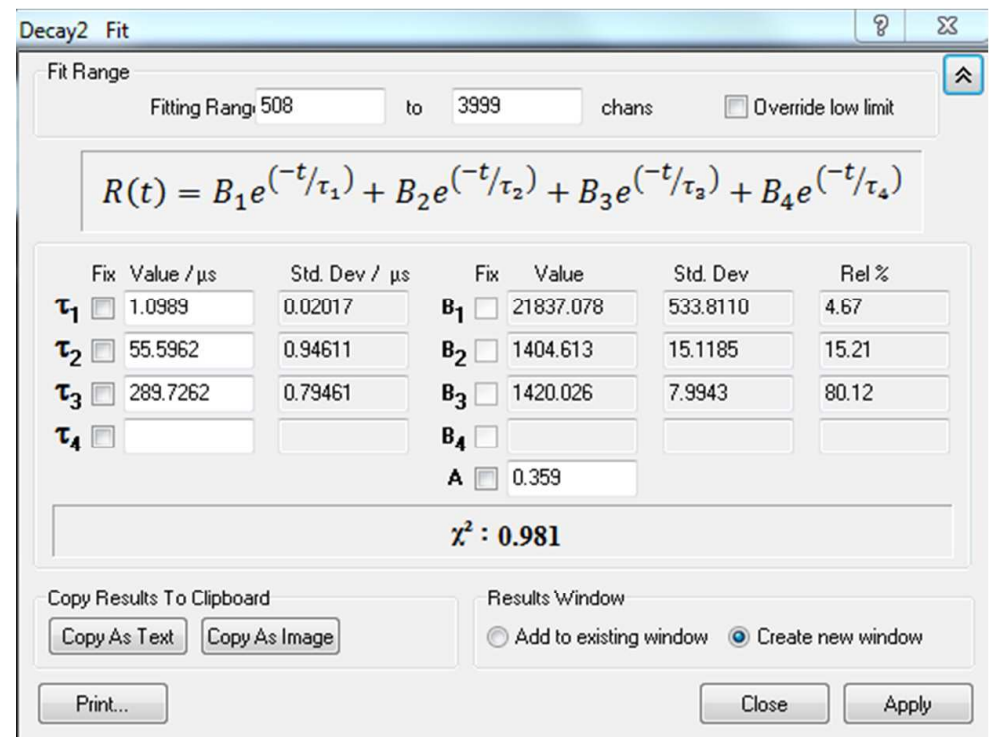

Figure S9. Luminescence intensity decay curve of [Eu(EP-pfdap $\left.)_{3}(\operatorname{tpy})\right](20 \mu \mathrm{M})$ in $0.05 \mathrm{M}$ borate buffer of $\mathrm{pH} 7.2$ (top), and luminescence lifetime fitting equation and results (bottom). 

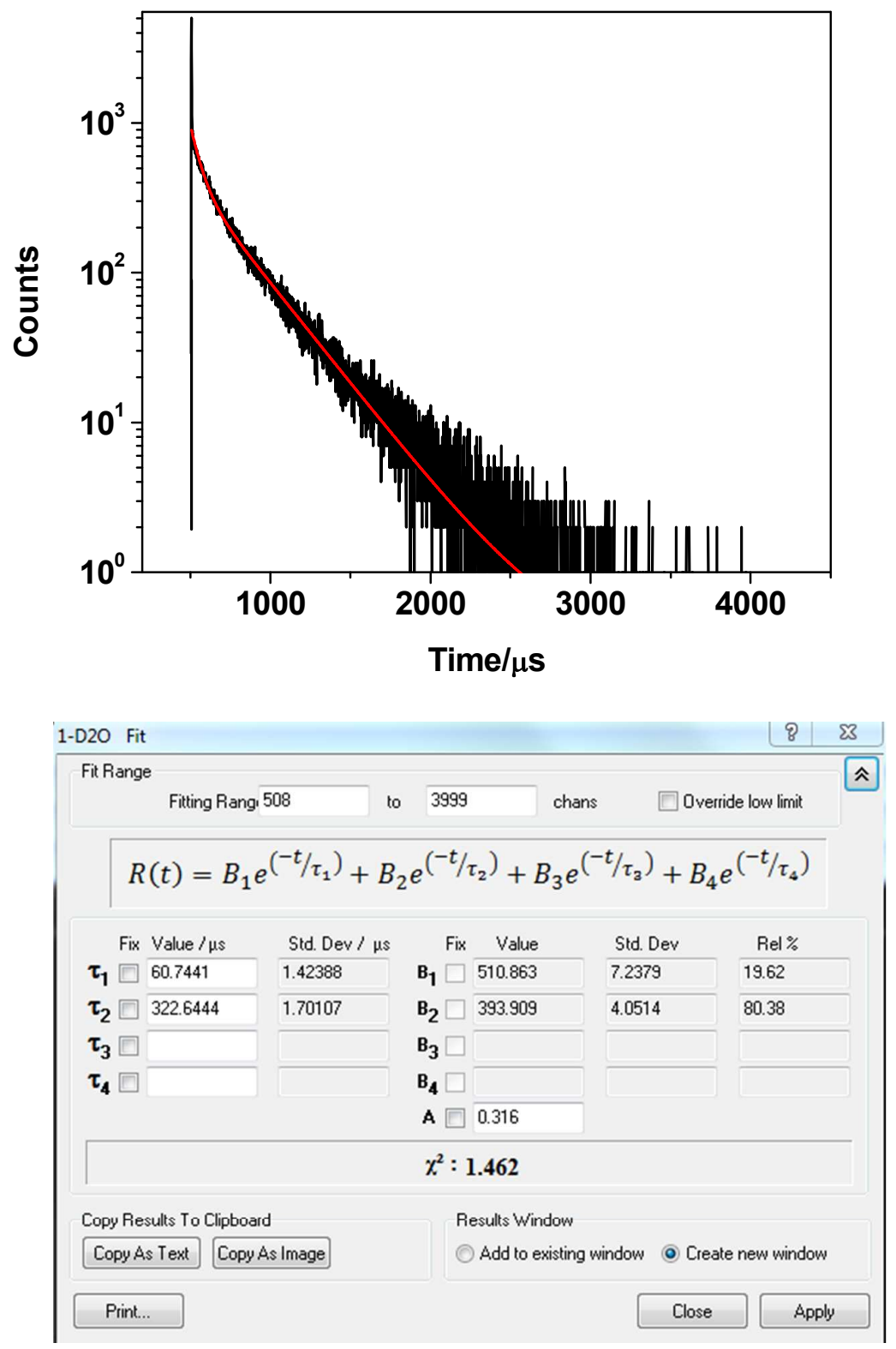

Figure S10. Luminescence intensity decay curve of [Eu(EP-pfdap) $)_{3}$ (tpy)] $(20 \mu \mathrm{M})$ in $\mathrm{D}_{2} \mathrm{O}$ (top), and luminescence lifetime fitting equation and results (bottom). 

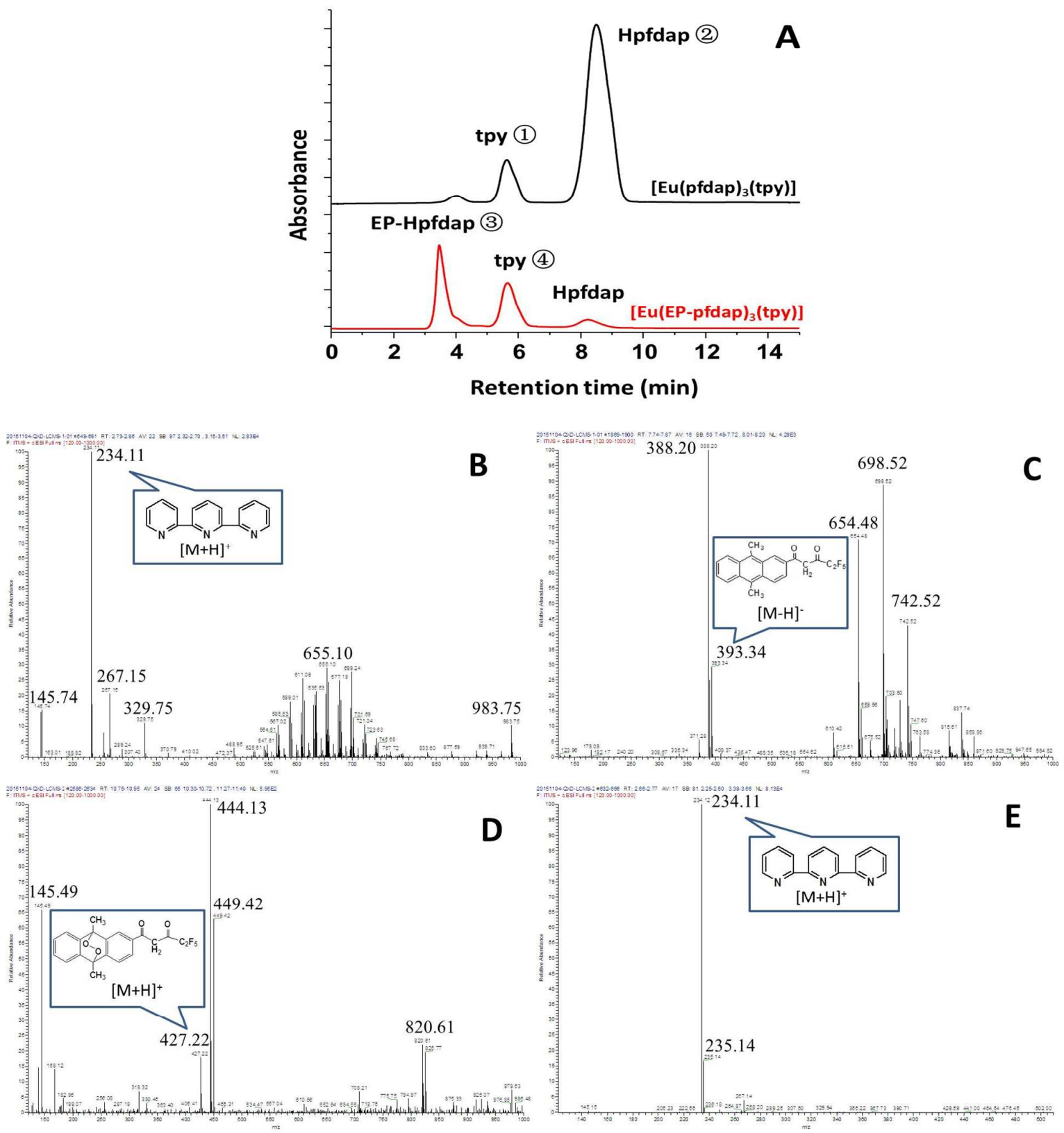

Figure S11. HPLC chromatograms of DTPA-treated $\left[\mathrm{Eu}(\mathrm{pfdap})_{3}(\mathrm{tpy})\right]$ and its oxidized products with ${ }^{1} \mathrm{O}_{2}(A)$, and mass spectra of HPLC signal 1 (B), signal 2 (C), signal 3 (D) and signal 4 (E). 


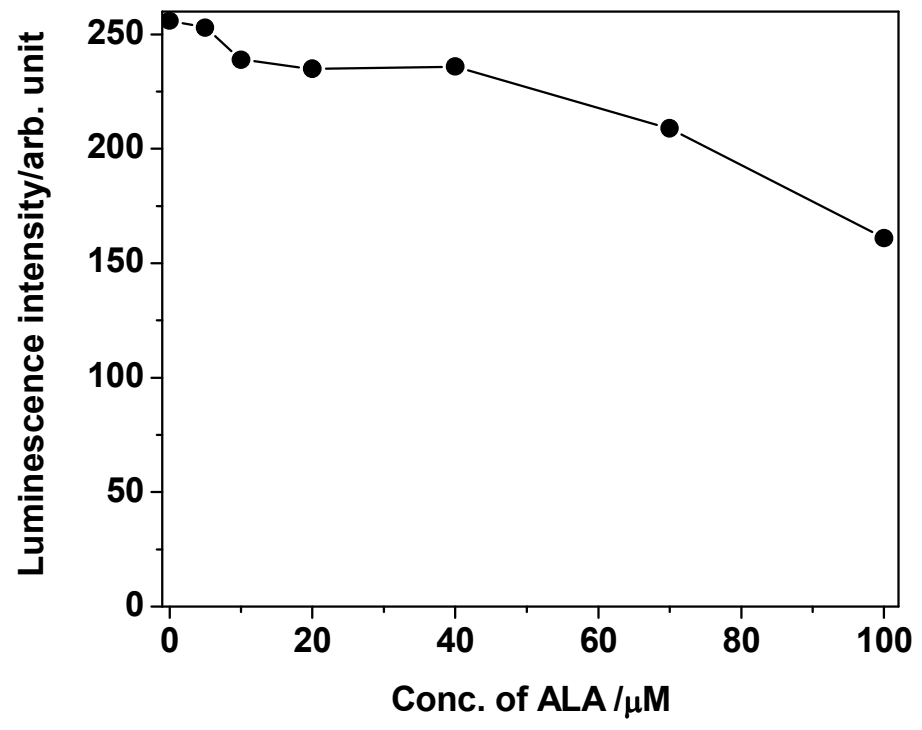

Figure S12. Time-gated luminescence intensity changes of $\left[\mathrm{Eu}(\mathrm{EP}-\mathrm{pfdap})_{3}(\mathrm{tpy})\right](3.0 \mu \mathrm{M})$ in the presence of different concentrations of ALA in $0.05 \mathrm{M}$ borate buffer of $\mathrm{pH} 7.2$ containing $0.25 \%$ cremophor C040. 


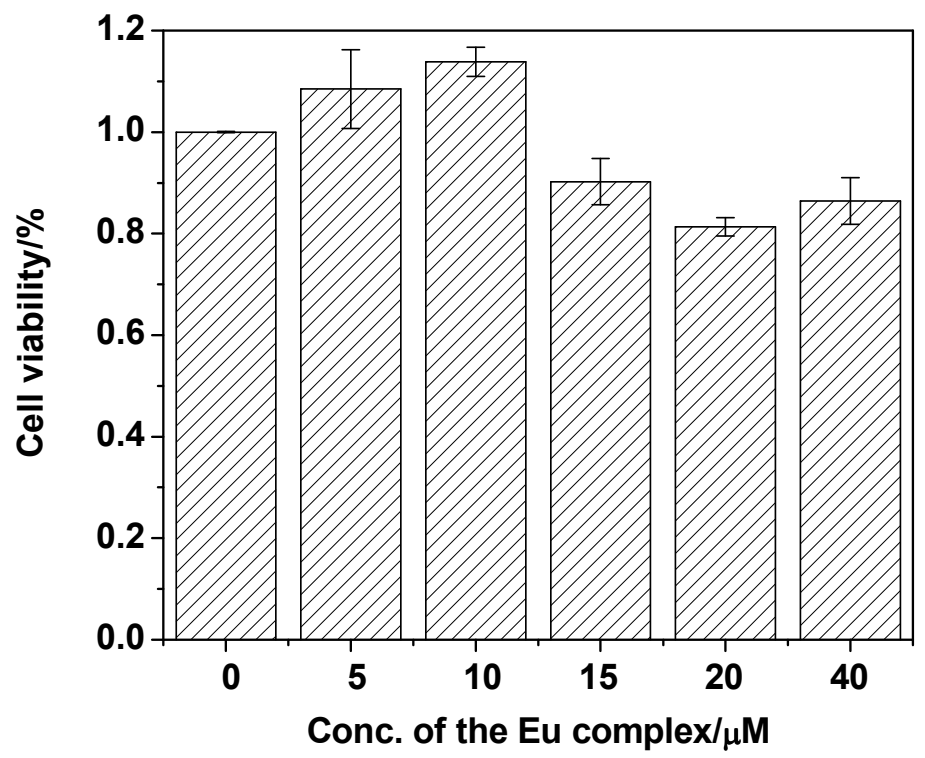

Figure S13. Viabilities of HepG2 cells after incubated with different concentrations of $\left[\mathrm{Eu}(\mathrm{pfdap})_{3}(\mathrm{tpy})\right]$ for $24 \mathrm{~h}$. 


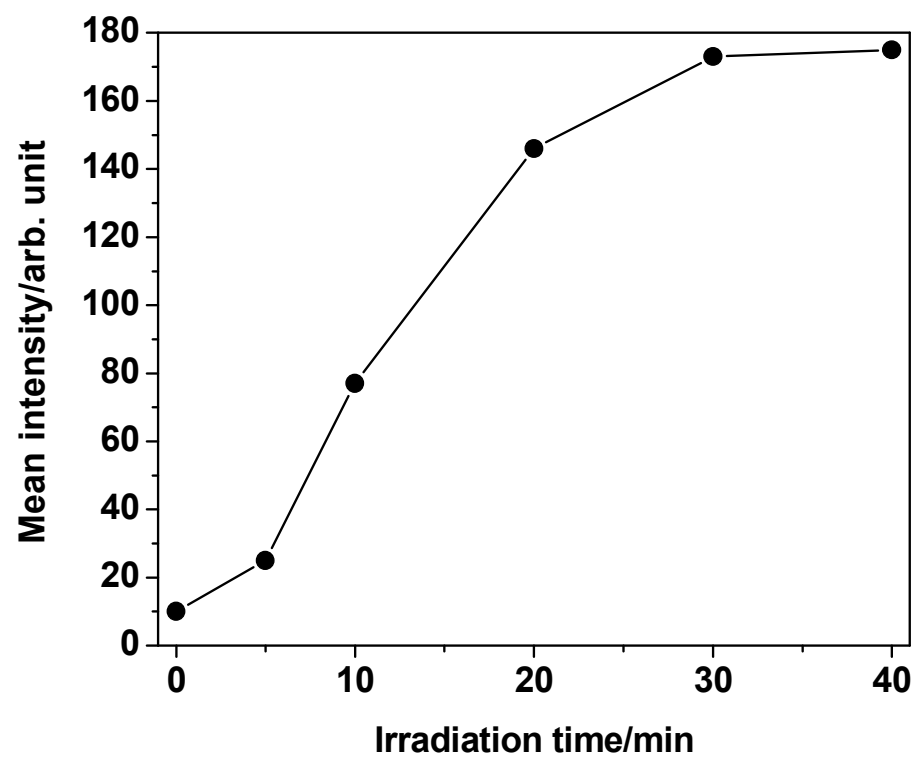

Figure S14. Intracellular luminescence intensities of the cells in Figure 7 at different irradiation times. 


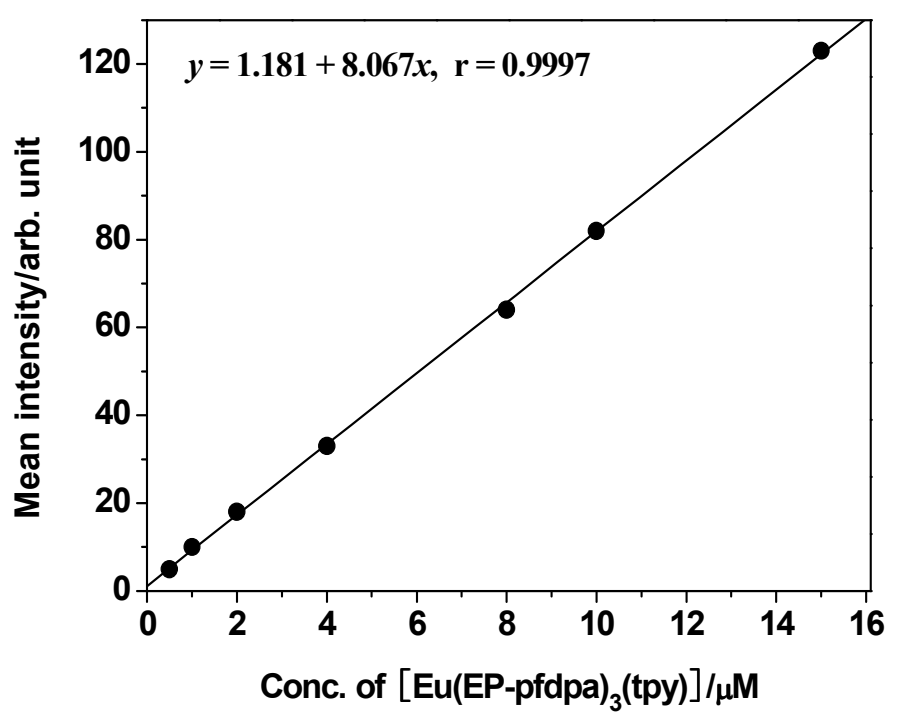

Figure S15. Luminescence dilution curve of [Eu(EP-pfdap) $\left.)_{3}(\mathrm{tpy})\right]$ measured on the laboratory-use true-color time-gated luminescence microscope. 